\title{
Benchmarking and Objective Selection of Technologies for Housing in India Using Quality Function Deployment
}

\author{
"Virendra Kumar Paul and Varun Seth
}

\begin{abstract}
Published online: 24 November 2017
To cite this article: Virendra Kumar Paul and Varun Seth. (2017). Benchmarking and objective selection of technologies for housing in India using quality function deployment. Journal of Construction in Developing Countries, 22(Supp. 1): 63-78. https://doi.org/10.21315/jcdc2017.22.supp1.4
\end{abstract}

To link to this article: https://doi.org/10.21315/jcdc2017.22.supp1.4

\begin{abstract}
The paper identifies technology as a key solution for the challenges of sustainability and quality in housing and recognizes benchmarking as a tool for selection of appropriate technologies. Suitability of technologies for housing has been explored in respect of functional needs, sustainability needs, and performance standards. These issues have brought out the need for an objective methodology for selection of appropriate technologies, especially for mass housing. The objective framework has been developed by identification of needs of large scale projects, assessment of current issues and their shortcomings and development of objective parameters. Quality Function Deployment (QFD) has been used as tool for benchmarking. The case example of the technologies promoted by Government of India for "Housing for All" Mission has been taken up for development of the framework and benchmarking. Findings from the QFD process highlight that these emerging technologies cater to limited building elements and not for the building system as a whole. Inconsistencies amongst performance of these technologies on various parameters have been demonstrated. It is concluded that assessment and benchmarking of technologies give useful insights into the comparative performance of each of these technologies and is hence, a useful tool for selection of appropriate technology for housing.
\end{abstract}

Keywords: Benchmarking, Quality Function Deployment, Housing construction technology, Selection methodology

\section{INTRODUCTION}

The National Housing Bank (2013) has estimated housing shortage in urban India at 18.78 million units in 2012. McKinsey Global Institute (2010) projects the growth of Indian urban population from 340 million in 2008 to 590 million by 2030 and KPMG (2014) projects that nearly 110 million new houses will be needed by 2022. Furthermore, the housing sector faces challenges like demand and supply constraints, land availability and shortage, financial and operational constraints like pressure on land and infrastructure, lack of clear titles of land, and encroachment (National Housing Bank, 2013). Shortage of housing gets combined with issues like expensive and scarce building materials and components, poor management of construction and industrial waste and mounting pressure on non-renewable resources to create a highly unsustainable scenario of housing in developing countries (Celly, 2007). However, development and use of cost-effective alternate construction technologies holds the potential to reduce the cost of construction by

Department of Building Engineering and Management, School of Planning and Architecture, New Delhi, INDIA

"Corresponding author: virendrakumarpaul@gmail.com 
optimising the quantity of materials used and reduce the ecological footprint by using alternate low embodied energy materials (Sengupta, 2008). Moreover, it can be said that technology holds great potential to provide solutions to the challenges of affordability, sustainability, and quality of housing.

India is currently deploying a considerable number of technology options for mass housing without detailed technical evaluation. The Performance Appraisal Certification Scheme (PACS) of BMTPC (2015), which recommends such technologies at the government level in India is largely driven by self-declared technical information for commercial promotion but not sufficient for comparative analysis for technology selection. In order to realise the potential benefits of technology, developers need to adopt a rational approach to determining performance of their technologies. The technology developers, in turn would need to compare technologies with respect to best practices and performance standards to identify areas of improvements. Hence, benchmarking of technologies is imperative for developing a robust framework for creating Sustainable and Social "Housing for All". Quality Function Deployment (QFD) is one such tool suggested for functional improvement of building systems, which can be explored to meet the need for developing a benchmarking approach for housing technologies as well. This paper explores QFD as a tool that can be used for benchmarking of technologies for housing based on suitability and performance driven parameters for emerging housing specific technologies.

\section{SUITABILITY OF TECHNOLOGIES FOR HOUSING}

Use of conventional building materials and techniques is putting pressure on our finite resource base and is leading to escalation in building cost, which in turn is leading to unaffordable shelter. Use of renewable and recycled building materials, development of factory made building systems and industrialisation of housing construction are the need of the hour (Jha, 2014). Building professionals need to evolve and employ techniques and designs that are appropriate to such contemporary context. Thus, the process of determining suitability of technologies, considering parameters relevant to the context and inherently including benchmarking approach is the prerequisite for technology implementation.

\section{Functional Needs}

The technology selection process needs to be primarily rooted on the application of building codes and performance standards, harmonization of common practices, procedures, and products specifications that allow compatibility across regional diversity and building safety to define functional needs. Thus, determining technology centric functional needs is critical to the local context.

\section{Sustainability Needs}

Construction technology selection is required to be relevant to local context, but also to the needs that entail creating resilient urban settlements responsive to climate change and other globally recognised concerns (UN-HABITAT-III-17, 2015). Hence, selection of technologies for housing construction must consider comprehensive 
sustainability determinants. Sustainable buildings benefit health, wellbeing, economic productivity, environmental sustainability, and social integration to form fundamental constituents of sustainable development (UNEP, 2013a). Body of knowledge on sustainable buildings is well developed and subsequently rating systems have evolved based on criteria like energy efficiency, use of materials, water efficiency, occupant comfort, and sustainable site development. UNEP (2013a) too enlists these parameters for addressing the environmental aspects of sustainability. The aim of creating a selection process inclusive of sustainability ensures refrain from infringing into the needs of the larger ecosystem (UN Economic and Social Council, 2015).

Sustainable buildings currently adopt green building guidelines that focus on the aspects of requirements related to aforementioned criteria, which are essentially driven by industrial technologies. Such guidelines and rating systems undermine sustainability framework, especially in relation to social and economic determinants. Healthy living, ease of maintenance and refurbishment, treating waste management as an integral part of housing development, and efficiently distributing and improving upon social infrastructure and services is crucial for creating better societies through sustainable housing development (UNEP, 2013b). The social parameters are becoming increasingly important as the Sustainable Social Housing Initiative of the United Nations Environment Programme (2013), also aims at promoting social cohesion and contributing to meeting the housing needs of various social groups. These include marginalised and vulnerable groups that require facilitating universal design principles, addressing gender disparities, and encouraging socially mixed communities. This requires taking into account the social and territorial peculiarities, supporting the protection and enhancement of landscapes, and historical and cultural heritage (UNEP, 2013a). Therefore housing technology selection needs to be founded on a well-conceived sustainability framework.

\section{Performance Codes and Standards}

Performance of construction technologies is ensured through compliance to national and international codes and standards, which could be broadly categorised as performance based, such as ISO 6240 and 6241 and the other as prescriptive directions, such as National Building Code of India-2005 (NBC) and European Commission Construction Product Directive etc. In India, PACS has also been promoted through self-disclosure by the technology promotors. It is observed that there is a need to address functional and sustainability parameters in a holistic manner to facilitate establishment of benchmarks and selection of technologies. Considering this as current limitation, parameters were identified by referring to NBC and Indian Standard (IS) codes for the purpose of this paper.

\section{OBJECTIVE SELECTION FRAMEWORK FOR TECHNOLOGIES}

The selection framework is required to be developed on need-specific objective criteria and performance standards. It is imperative that reliable benchmarking of technologies is made possible in spite of the fact that technologies may be dissimilar in terms of technical parameters yet offering comparable functional solutions from 
stakeholder's perspective. In this context, it may be inappropriate to compare alternatives on the basis of codes and standards alone, primarily because such an approach tends to evaluate solutions in terms of specific elements rather than the entire building system. Therefore, the framework for benchmarking and objective selection is proposed to be developed for building system wide application and for comprehensive objective benchmarking.

\section{Methodology for Developing Framework}

The methodology adopted for developing the objective selection framework for this paper includes first identifying the needs of large-scale target projects, which necessitate the requirement of assured performance of technology options. For the purpose of assessment of needs for mass housing, the "Housing for All by 2022" policy is being considered. Selection framework shall be validated through the case of emerging technologies being promoted by the Government of India, under Technology sub-mission of Housing for All Policy. Next, objective parameters for the areas identified for benchmarking are developed in terms of demanded qualities and quality characteristics. After development of objective parameters for benchmarking, the process of QFD is implemented for benchmarking of technologies based on the inter-relationship of demanded qualities with the quality characteristics. The results of the QFD process are then analysed to obtain comparative metrics of performance of the technologies under consideration. Comparative metrics obtained from the QFD process give useful insights into the holistic performance of the technologies with respect to each other as well as with respect to performance standards and provide a sound base for making a decision for selection of technology for housing.

\section{Emerging Technologies under Indian Government's Technology Sub-mission}

The Building Materials and Technology Promotion Council (BMTPC), Ministry of Housing and Urban Poverty Alleviation, Government of India has been studying and evaluating prospective innovative construction systems for mass housing developed within the country and aboard. Based on their technical suitability, BMTPC has recommended eight technologies at present, which include "Monolithic Concrete Construction System using Plastic-Aluminium Formwork", "Monolithic Concrete Construction System using Aluminium Formwork", "Expanded Polystyrene Core Panel System", "Industrialized 3-S System using Precast RCC Columns, Beams and Cellular Light Weight", "Concrete Precast RCC Slabs Speed Floor System", "Glass Fibre Reinforced Gypsum (GFRG) Panel Building System", "Factory Made Fast Track Modular Building System", and "Light Gauge Steel Framed Structures (LGSF)" (Ministry of Housing and Urban Poverty Alleviation, 2015). These technologies are being considered for their application and validation of proposed selection methodology.

These technologies have been compared and assessed on a generic framework as a guide to their selection and the same is presented in Table 1. The technical data presented in Table 1 is however insufficient to describe these as alternatives in respect of functional and sustainability needs.

As may be observed in the Table 1, the technologies are far from being an integrated building system. These technologies are specific to certain building elements and their performance is limited to the scope of application as a 
component rather than a comprehensive building solution. Observations specific to the performance related issues are as follows:

1. While technologies solely based on concrete and steel address the requirements of structural integration, other technologies rely on composite construction techniques, which may lead to problems associated with the use of dissimilar materials in one place and the integrity of joints.

2. Some of the proposed technologies address the requirements of specific building elements viz. super structure, walls or floors but do not look at the holistic perspective of the complete building system.

3. The durability characteristics of most of the technologies have been defined only for the constituent panels/elements.

4. Thermal properties of these technologies show huge variations, which correspond to their basic materials and optimisation for thermal performance of the complete building is missing.

5. The quality assurance process defined for most technologies is only valid up to the constituent panels or materials and no specific process has been defined for quality assurance of the complete building. Furthermore, some of the proposed technologies do not have any quality assurance process in place.

6. The breakeven points for viability of adopting these technologies are also quite high and this poses a challenge for adoption of such technologies by real estate developers.

It may be argued that the selection of a suitable technology is not possible until and unless they are compared to well established performance standards based on existing technologies. In such a scenario, the performance of these technologies could be evaluated in respect of their scope of application to facilitate selection decision for housing. Hence, it becomes imperative that an objective benchmarking and "building system wide" selection methodology is adopted and new technologies are validated against the established benchmarks.

\section{Need for benchmarking and objective selection}

Benchmarking is the process of comparing performance based parameters of a specific process or technology to a standard or best practice (Balachandran, 2010). The process of benchmarking allows innovators to assess areas of improvement in their technology and adopt standards that are comparable to best practices (Horne and Hayles, 2008). In order to develop a holistic approach towards achieving the functional and sustainability needs of housing in the country, the process for selection of technologies needs to quantitatively assess the performance of technologies with respect to industry best practices and performance standards on parameters of functional and sustainability needs. Validation of the performance of any technology through such a benchmarking process is critical for the success of the technology. ISO 9000:2000 quality management system standards define validation as confirmation through the provision of objective evidence that the requirements for a specific intended use or application have been fulfilled. Hence, an objective system for selection of appropriate technologies based on comparison with performance benchmarks will prove to be instrumental in developing an evidence-based methodology for assessing, validating, and implementing building technologies aimed at achieving "building system wide" performance. 


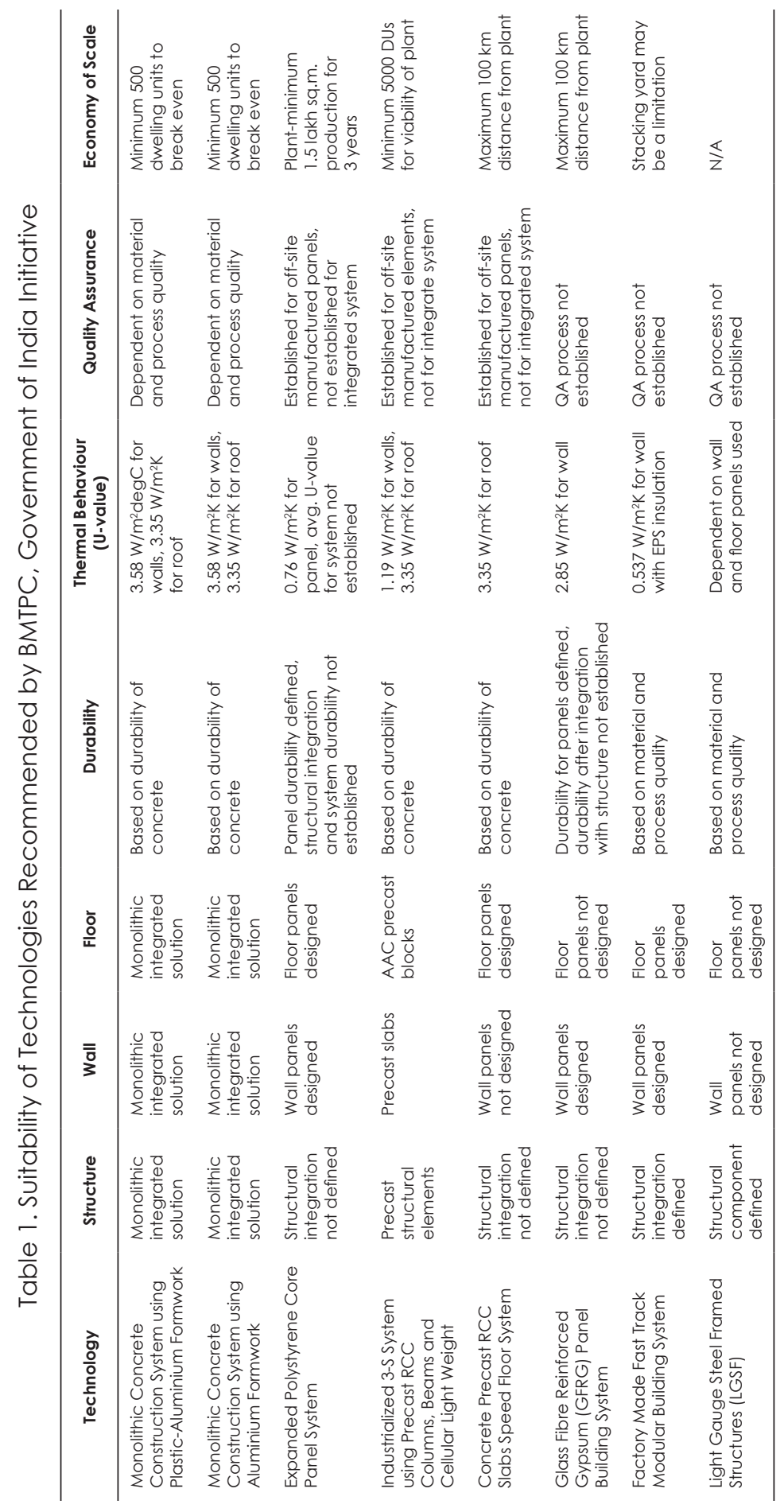




\section{PARAMETERS FOR BENCHMARKING AND OBJECTIVE SELECTION}

Conventional practices are generally labour-driven and involve minimal or no mechanization. This results in housing solutions that are characterized by low durability, slow construction process, and poor performance against functional and sustainability needs. Chohan et al. (2015) identified determinants of housing quality as unit layout, workmanship in construction, garbage collection system, environmental conditions, appearance/design, internal conditions, and accessibility. Any housing must have performance above the tolerable standard, should be free from serious defects, should be energy efficient, should have modern facilities, and must be healthy, safe, and secure. This can be achieved by working on parameters of housing quality, which include functionality, appearance, context, buildability, sustainable characteristics in town and landscape, quality of urban realm, accessibility and local permeability, legibility, adaptability, diversity, and choice (Chohan et al., 2015).

Thus, selection of technologies for mass-scale housing construction with diverse geo-climatic, socio-cultural, economic, and hazard-vulnerable conditions requires an all-inclusive approach to address functional needs like quality, durability, performance, and sustainability needs like environmental as well as socio-economic and cultural concerns. Based on the literature review on functional, sustainability, and performance needs of housing, input parameters have been narrowed down to eight, namely: strength and stability; compliance to code and standards; functional requirements; construction management aspects; maintenance; environmental; and, economic and social sustainability. The same are presented in Table 2.

Table 2. Inputs for Benchmarking and Assessment Framework

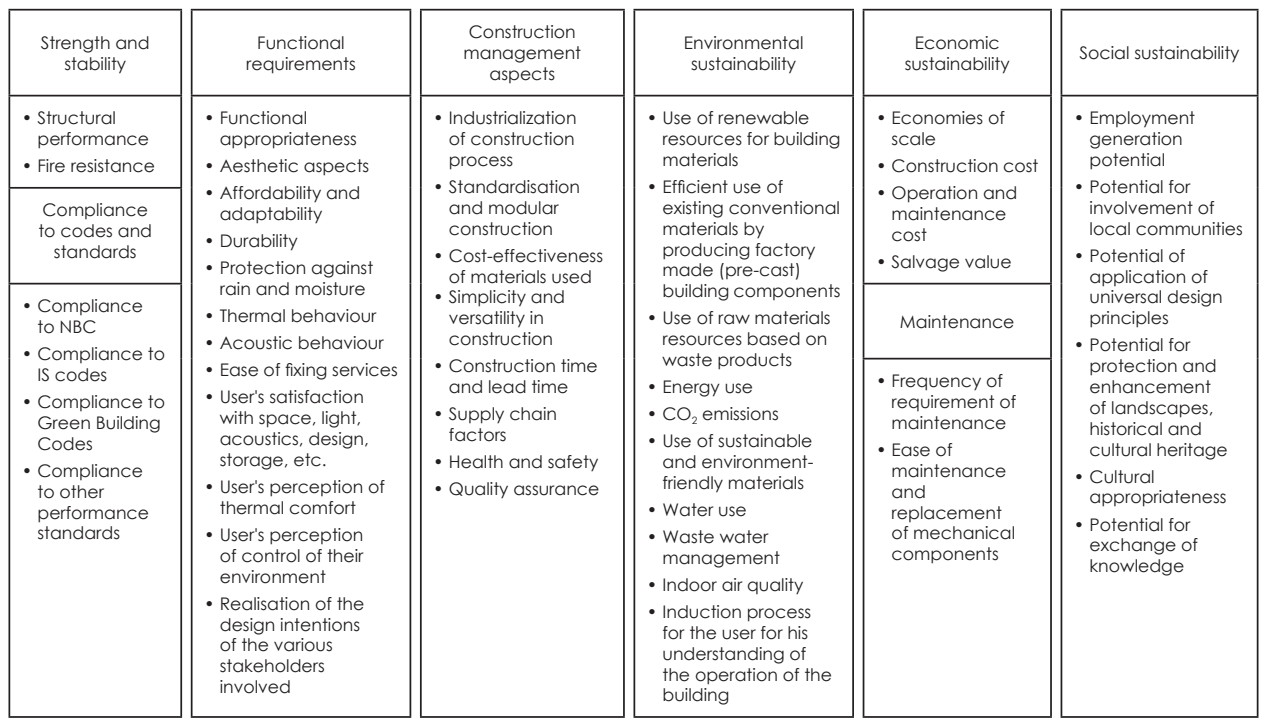




\section{ASSESSMENT AND BENCHMARKING USING QFD}

Performance assessment for technologies is often accomplished by benchmarking on competitors' product-development methods (Ettlie and Johnson, 1994). One of the common tool used for benchmarking and deriving requirements is QFD. Precisely understanding and documenting user needs is particularly important in housing because of the need to maximise the value perceived by final users under existing cost constraints and QFD is a widely-used tool for doing the same (Formoso, Leite and Miron, 2011). QFD is a management tool that provides a visual connective process for translating consumer needs into appropriate technical requirements for product-development, which focusses on consumer-oriented and high-quality products (Bouchereau and Rowlands, 2000). QFD presents a powerful tool to aid the translation of qualitative consumer requirements into precise quantitative technical requirements. The eight parameters identified in the paper are also qualitative in nature and need to be translated into quantifiable technical requirements to achieve reliable performance benchmarking. This makes QFD a fit candidate for exploring the development of a methodology for benchmarking and objective selection of technologies for housing in India.

QFD uses the House of Quality (HOQ) approach to document desired qualities in a technology and connecting these to their means of accomplishment. QFD starts with an input list of objectives or root consumer needs for the target market or segment for which the technology is being developed. The HOQ then translates these objectives into engineering characteristics and targets. In subsequent HOQs engineering targets are translated into design requirements and design requirements are translated into desired parts characteristics (Ettlie and Johnson, 1994). QFD process used for housing technology benchmarking, using the eight input parameters presented in Table 2 is shown in Figure 1.

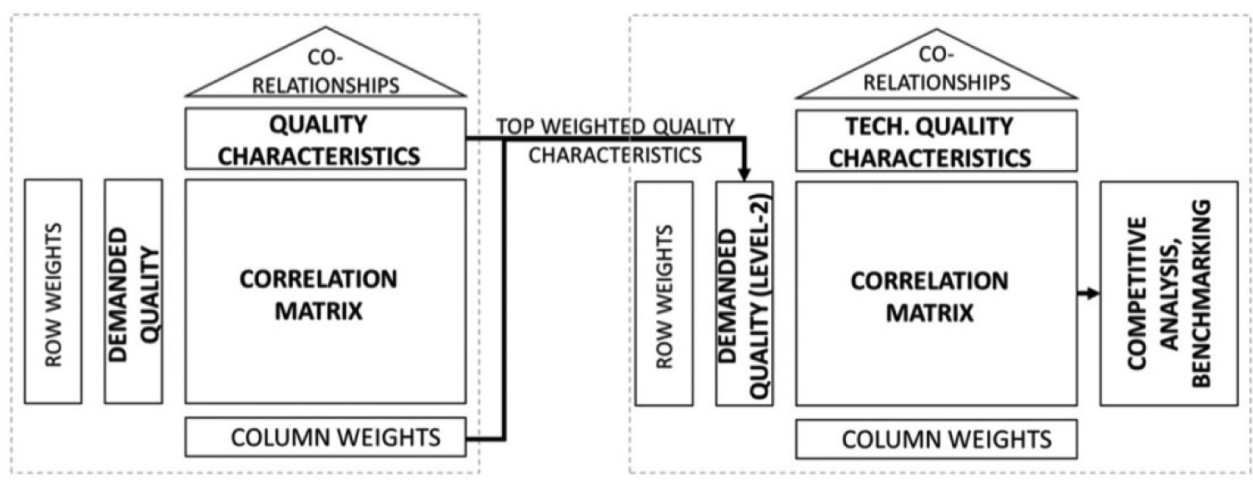

HOUSE OF QUALITY: LEVEL 1- DESIGN REQUIREMENTS

HOUSE OF QUALITY: LEVEL 2- TECHNOLOGY REQUIREMENTS

Figure 1. QFD Process for Housing Technology Benchmarking

Based upon a sequence of HOQs, QFD provides a logical and systematic methodology for capturing and organizing the requirements translations necessary for effective and efficient new technology selection and implementation. In the case of selection of technologies for housing, $\mathrm{HOQs}$ are required to be developed at two levels, namely, design requirements and technology requirements. 


\section{HOQ-Level 1: Design Requirements}

The first level of $\mathrm{HOQ}$ translates demanded quality of housing into design characteristics. The demanded qualities include broad aspirational, functional, technical, environmental, and socio-economic characteristics, which are required for healthy living in housing. The next step is to correlate these demanded qualities with quality characteristics. Quality characteristics are ways and measures that can be used to achieve the demanded qualities in housing. At the first level these may consist of specific quantitatively measurable characteristics as well as vaguely measurable qualitative characteristics. Demanded qualities and quality characteristics for the first level $H O Q$ are listed in Table 3. These demanded qualities and quality characteristics serve as the inputs for the first level $\mathrm{HOQ}$, where correlations are developed to derive top weighted quality characteristics.

Table 3. Demanded Qualities and Quality Characteristics for Level-1 HOQ

\begin{tabular}{|c|c|c|}
\hline Demanded Qualities & Quality & ics \\
\hline $\begin{array}{l}\text { - } \text { Adequacy } \\
\text { - Resilience } \\
\text { - Environmental } \\
\text { sustainability } \\
\text { - Infrastructure } \\
\text { - Operations and } \\
\text { maintenance } \\
\text { - Cultural } \\
\text { appropriateness } \\
\text { - Economic } \\
\text { sustainability } \\
\text { - Social } \\
\text { sustainability }\end{array}$ & $\begin{array}{l}\text { - Efficiency of space } \\
\text { - Incrementalism, adaptability } \\
\text { - } \text { and flexibility } \\
\text { vaylighting and natural } \\
\text { - Location and accessibility } \\
\text { - Safety and security } \\
\text { - Green and social spaces } \\
\text { - Disaster risk reduction } \\
\text { - Energy use and } \mathrm{CO}_{2} \text { emissions } \\
\text { - Embodied energy } \\
\text { - Water management } \\
\text { - Indoor air quality } \\
\text { - Site planning and ecology } \\
\text { - Electricity demand }\end{array}$ & $\begin{array}{l}\text { - Water supply and sewerage } \\
\text { - Access infrastructure } \\
\text { - Telecommunication } \\
\text { - Durability } \\
\text { - Fire resistance } \\
\text { - Operational cost over life } \\
\text { cycle } \\
\text { - Response to local culture } \\
\text { - Affordability of housing } \\
\text { - Employment opportunities } \\
\text { - Universal design principles } \\
\text { - Involvement of local } \\
\text { - Incommunity in design process } \\
\text { - Incluity in design }\end{array}$ \\
\hline
\end{tabular}

The $H O Q$ developed at the first level is shown in Figure 2. Based on inputs from literature, the authors understanding and inputs from experts on the subject, correlation between demanded qualities and design characteristics is done by assigning relationship values of either 9 (strongly related characteristics), 3 (moderately related characteristics) or 1 (weakly related characteristics). The characteristics that are not related are left blank and the relationship value is considered to be zero. Importance weights are assigned to demanded qualities, which along with the correlation values form the basis of the calculation of the importance weights of the quality characteristics. The roof of the HOQ contains the inter-relationships between the quality characteristics. Top weighted quality characteristics from the first level $\mathrm{HOQ}$ are then taken to the second level $\mathrm{HOQ}$, which benchmarks technologies for housing. 


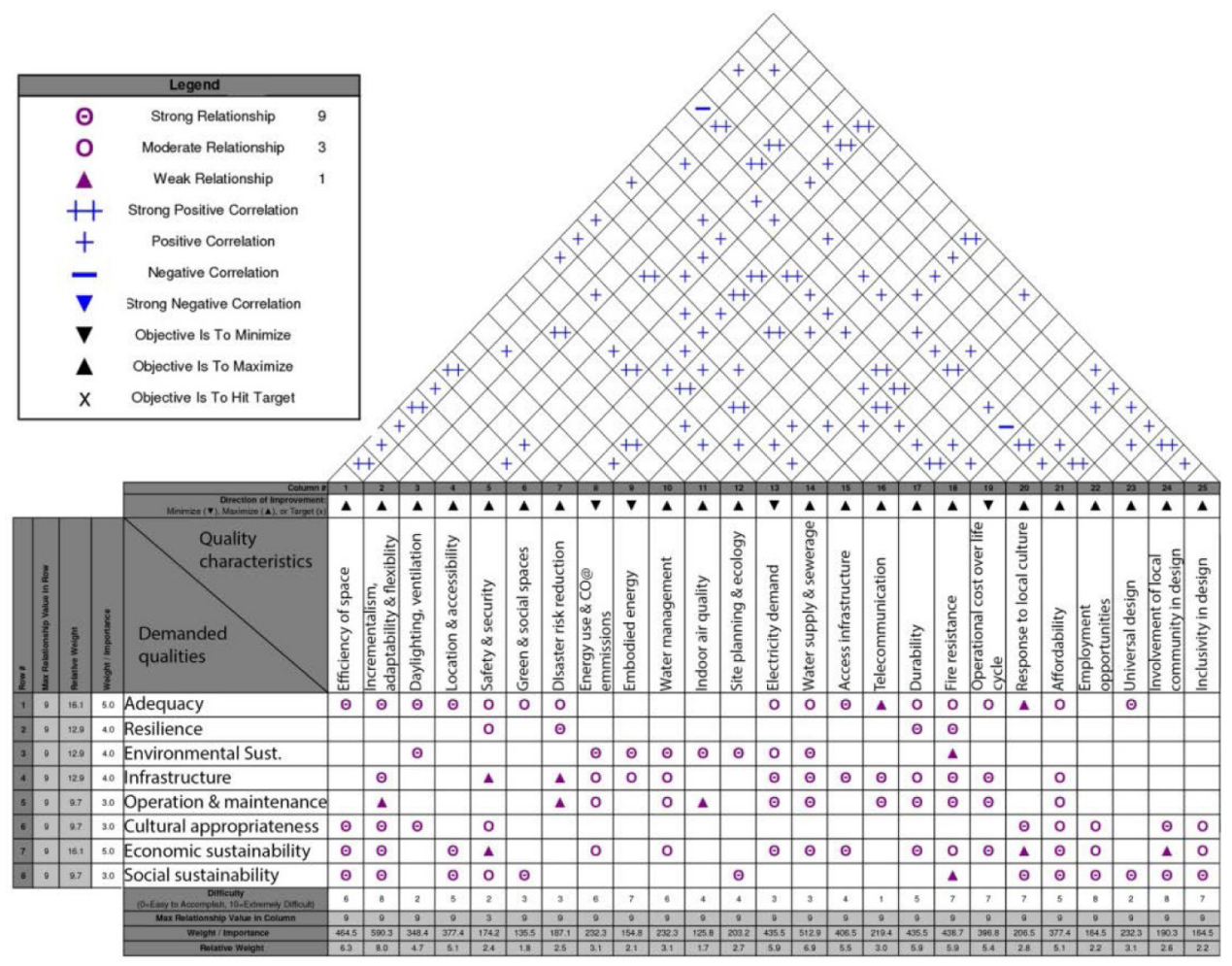

Figure 2. HOQ-Level 1

\section{HOQ-Level 2: Technology Requirements}

The top weighted quality characteristics from the first level $\mathrm{HOQ}$ are used as the demanded quality parameters in the second level HOQ. In this paper, the top six quality characteristics from first level $H O Q$ have been considered. Demanded qualities and technology quality characteristics for the second level $\mathrm{HOQ}$ are listed in Table 4.

Similar to Level $1 \mathrm{HOQ}$, demanded qualities are related to quality characteristics and quality characteristics are also inter-related. The second level $\mathrm{HOQ}$ is shown in Figure 3. In this second level $\mathrm{HOQ}$ matrix, quality characteristics are defined for performance of technologies and benchmarking is done for these considered technologies. Each quality characteristic is measured against wellestablished performance standards and target values are assigned based on application of performance standards in their particular context.

For demonstration of this process, four technologies being promoted by BMTPC, which comprise of building systems have been selected and compared. The four technologies are "Monolithic Concrete Construction using Plastic-Aluminium Formwork", "Expanded Polystyrene Core Panel System", 'Industrialised 3 S System", and "Factory Made Fast Track Modular Building System". 
Table 4. Demanded Qualities and Quality Characteristics for Level-2 HOQ

\begin{tabular}{ll}
\hline \multicolumn{1}{c}{ Demanded Qualities } & \multicolumn{1}{c}{ Quality Characteristics } \\
\hline - Efficiency of space & - Wall thickness \\
- Incrementalism, flexibility and & - Ease of modification/replacement of parts \\
- Edaptability & - U-value \\
- Wectricity demand & - Fenestration \\
- Durability & - Structural design \\
- Fire resistance & - Structural detailing against disasters \\
& - Fire rating of complete system \\
& - Ease of fixing/maintaining services \\
& - Detailing of joints \\
& - Quality assurance \\
\hline
\end{tabular}
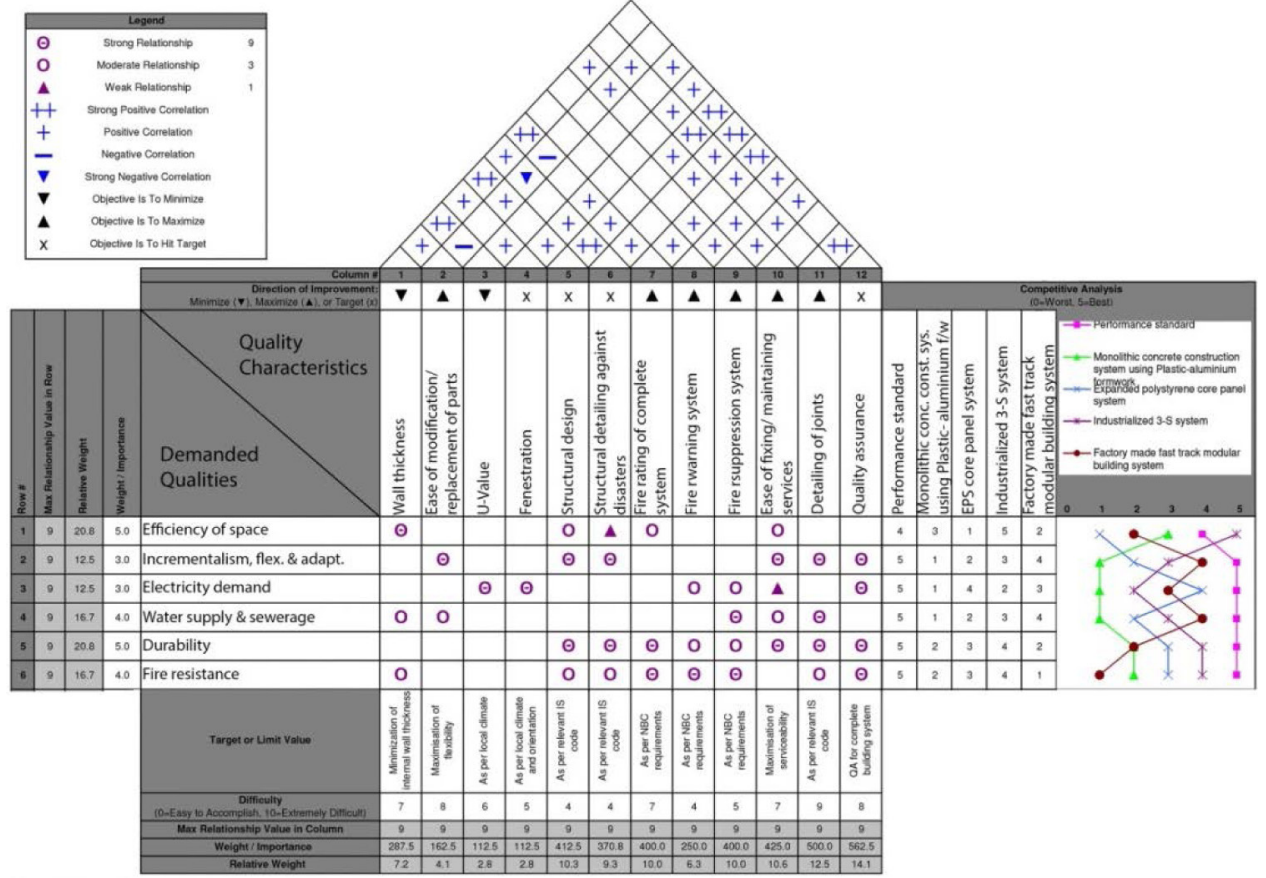

Figure 3. HOQ-Level 2

Based on the second level HOQ matrix, the performance of these technologies with respect to the demanded quality, quality characteristics, and their relationships has been tabulated in Table 5. For the calculation of ranks, the technologies have been first measured against their respective performance standard (Table 5) and then converted into performance ratios in which the performance standard is considered to bear the value of 1 . Performance ratio 


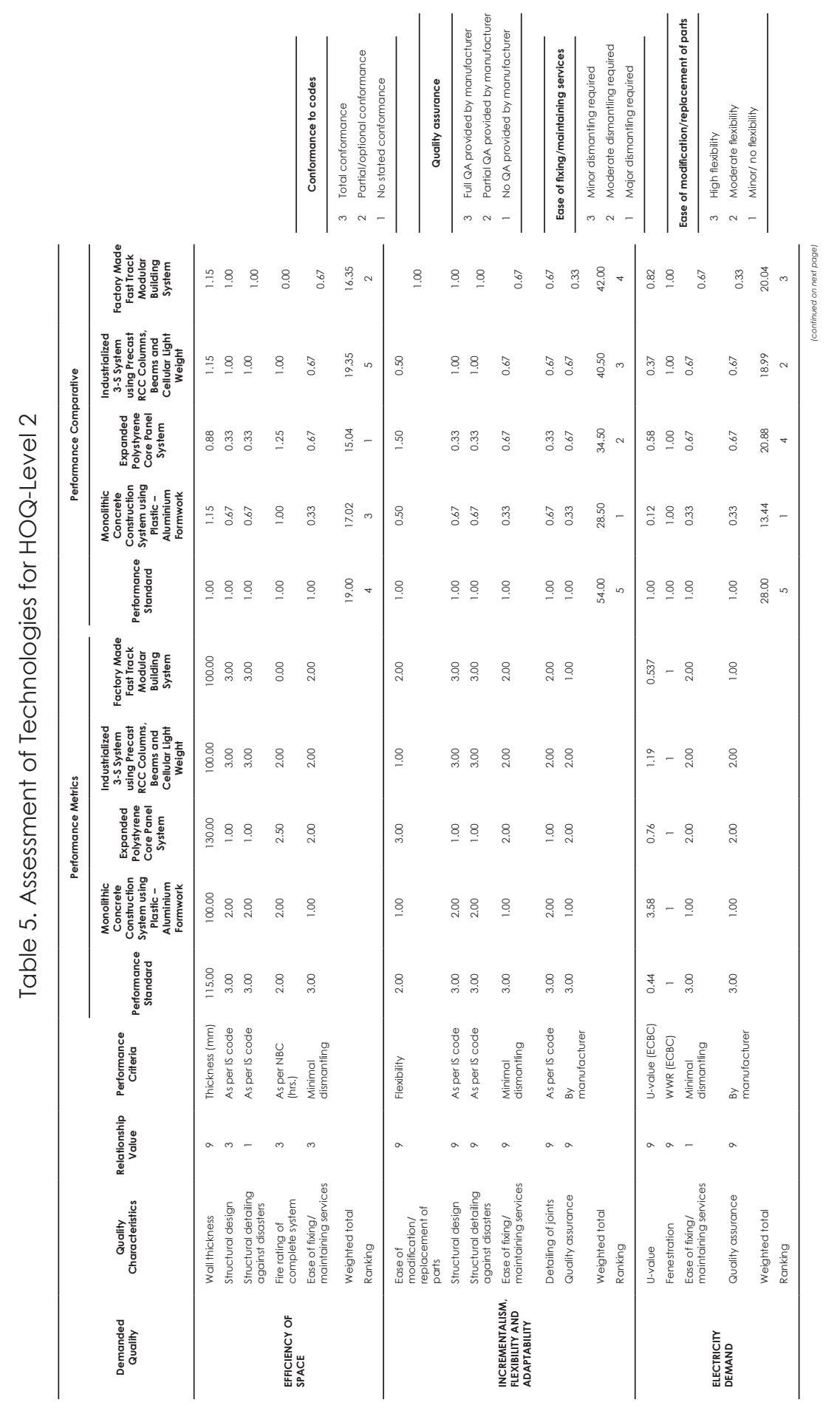




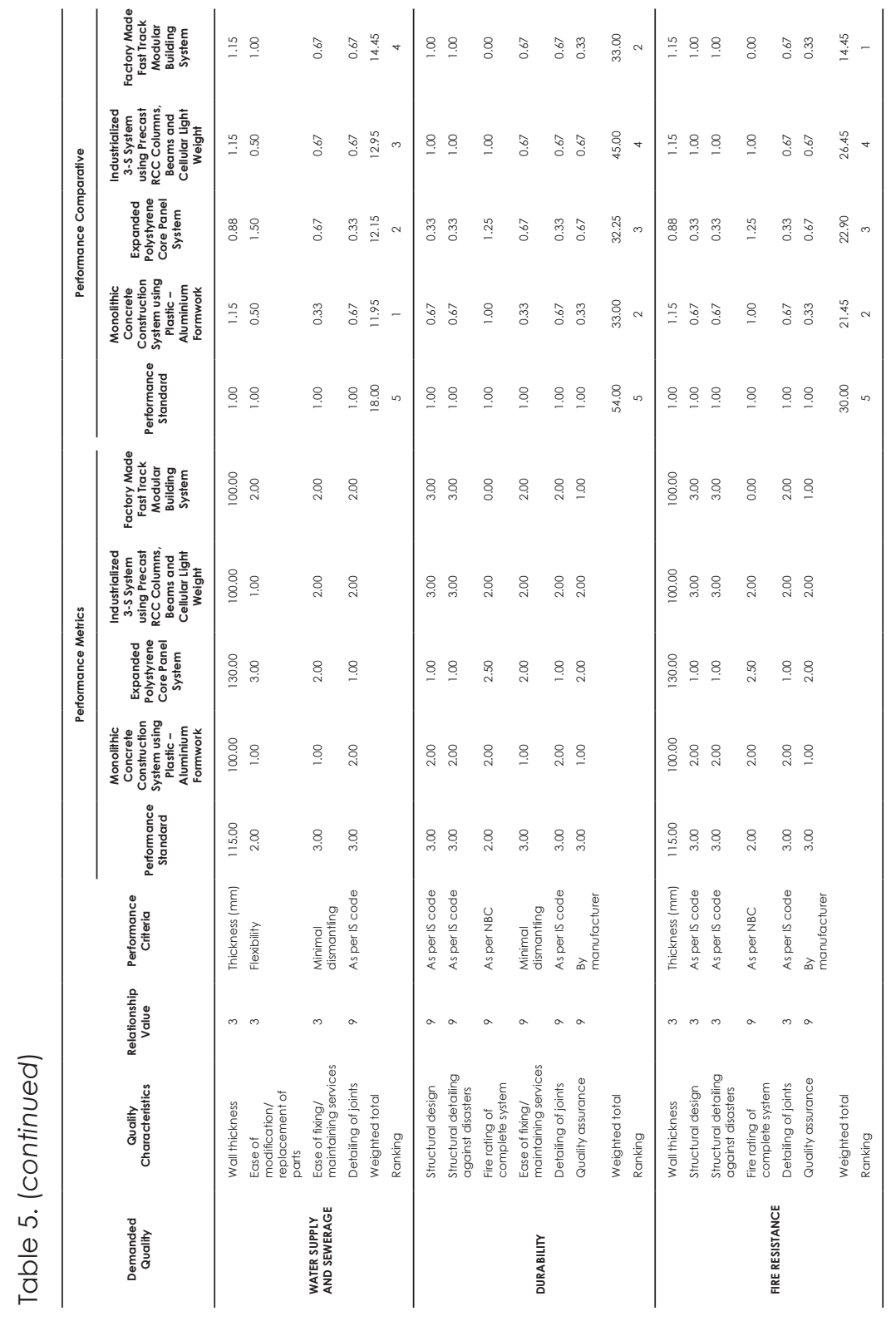


exceeding 1 indicates performance better than the performance standard and a ratio of less than 1 indicates performance worse than the performance standard. For quality characteristics where the performance criteria have been defined as conformance to codes and standards, a score of 3 has been assigned on full conformance, 2 on partial conformance, and 1 on non-conformance to the respective code. After the conversion of performance metrics into ratios, they are multiplied by their respective relationship values to get weighted scores for the technologies under each demanded quality and ranking is done on the basis of this weighted score.

\section{Findings from The QFD Process}

From the analysis of the four technologies with this technique, it is evident that all of the technologies underperform with respect to the performance standards, which in this case have been considered to be the National Building Code-2005, Indian Standard codes and the Energy Conservation Building Code-2007. The QFD process also gives a comparative analysis of performance of these technologies with respect to each other. From the comparative analysis, it may be inferred that the industrialised 3-S system has the highest performance among the four technologies compared by the QFD process. This inference has been drawn by totalling the competitive scores of the technologies obtained from the second level HOQ. However, from the comparative analysis graph (Figure 3), it becomes evident that the technologies also show large variations in terms of performance against various demanded quality parameters. For instance, Expanded Polystyrene Core Panel System on one hand fares well as compared to others in terms of reducing electricity consumption through the use of thermal insulation, but it fares poorly in terms of efficiency of space, flexibility, durability, and fire resistance. The Monolithic Concrete Construction using Plastic-Aluminium Formwork shows moderate performance in terms of efficiency of space, durability, and fire resistance, but fares poorly in flexibility, adaptability, and reducing electricity demand. Meanwhile, the Industrialised 3-S System fares well in efficiency of space, durability, and fire resistance, it shows moderate performance in flexibility, adaptability, and reducing electricity demand. However, the performance of all of the technologies is inferior as compared to the performance standards.

Thus, the process of assessment and benchmarking of technologies gives useful insights into the comparative performance of each of these technologies and is hence, a useful tool for selection of appropriate technology for housing.

\section{CONCLUSION}

The "Housing for All by 2022" mission has put forward a mammoth task of providing quality housing for those who cannot afford it and this has opened new avenues for large-scale innovation in the field of technology for housing. Need for large numbers of houses, inadequacies of existing construction technologies, and the need for faster and quality construction opens doors for research and development in the field of development of new and appropriate technologies. At present, technologies that are being developed focus on the technical aspects of certain structural and functional requirements. However, the development of a framework 
for benchmarking performance of these technologies against a broader domain of factors is needed for development of such technologies. The broad areas under which factors need to be considered are presented in this paper. It has been found that the emerging technologies cater to building elements and not holistic building systems. Inconsistencies among performance on various parameters and inadequacies in the current approach to technology assessment have been demonstrated through the use of QFD process. Hence, it is proposed that an objective framework for the assessment of suitability and performance criteria for such technologies, like the one demonstrated in this paper, is a useful tool for selection of appropriate technologies to create adequate housing. For successful development of such a framework, development of benchmarking standards for performance of building systems is of utmost importance. It is imperative that the selection of new technologies has to be based on this objective methodology against the defined parameters and with reference to the established benchmarks of performance to achieve the target of providing quality housing within the specified time constraint.

\section{ACKNOWLEDGEMENTS}

We sincerely thank the Department of Building Engineering and Management, School of Planning and Architecture, New Delhi for providing us the resources to conduct the study. We further thank the faculty at the department for their invaluable suggestions and inputs. We also thank our families and friends for their constant support and encouragement.

\section{REFERENCES}

Balachandran, G. (2010). Methodology and perspectives of business studies. New Delhi: Ane Books Pvt Ltd.

Bouchereau, V. and Rowlands, H. (2000). Methods and techniques to help quality function deployment (QFD). Benchmarking: An International Journal, 7(1): 8-20. https://doi.org/10.1108/14635770010314891

Celly, R.K. (2007). Low cost, energy efficient and environment friendly housing technologies for friendly housing technologies for developing countries. Sanjaya Lall Memorial Conference on India-Africa Cooperation, Trade and Investmen. New Delhi, India, 10-14 September 2007. Available at: http://www. unido.org/fileadmin/import/75382_070912_Sess 1002_Cellylowcosthousing. pdf [Accessed on 16 June 2016].

Chohan, A.H., Che-Ani, A.I., Shar, B.K., Awad, J., Jawaid, A. and Tawil, N.M. (2015). A model of housing quality determinants (HQD) for affordable housing. Journal of Construction in Developing Countries, 20(1): 117-136.

Ettlie, J.E. and Johnson, M.D. (1994). Product development benchmarking versus customer focus in applications of quality function deployment. Marketing Letters, 5(2): 107-1 16. https://doi.org/10.1007/BF00994101

Formoso, C., Leite, F. and Miron, L. (2011). Client requirements management in social housing: A case study on the residential leasing program in Brazil. Journal of Construction in Developing Countries, 16(2): 47-67. 
Horne, R. and Hayles, C. (2008). Towards global benchmarking for sustainable homes: An international comparison of energy performance of housing. Journal of Housing and the Built Environment, 23(2): 119-130. https://doi. org/10.1007/s10901-008-9105-1

Jha, C.N. (2014). Alternate and emerging technologies for housing and building construction. National Seminar on Green Affordable Housing. India Habitat Centre, New Delhi, 13 June 2014. Available at: http://www.naredco.in/pdfs/ BMTPC_CN-Jha.pdf [Accessed on 16 June 2016].

KPMG. (2014). Decoding housing for all by 2022. KPMG International. Available at: from https://assets.kpmg.com/content/dam/kpmg/pdf/2014/09/DecodingHousing-for-all-2022.pdf [Accessed on 16 June 2016].

McKinsey Global Institute. (2010). India's urban awakening: Building inclusive cities, sustaining economic growth. New York: McKinsey Global Institute.

Ministry of Housing and Urban Poverty Alleviation. (2015). Compendium of prospective emerging technologies for mass housing. New Delhi: Ministry of Housing and Urban Poverty Alleviation, Government of India.

National Housing Bank. (2013). Report on trend and progress of housing in India. New Delhi: National Housing Bank. Available at: from http://www.nhb.org.in/ Publications/Progress-report-2013-ENGLISH.pdf [Accessed on 26 April 2016].

Sengupta, N. (2008). Use of cost-effective construction technologies in India to mitigate climate change. Current Science, 94(1): 38-43.

UN Economic and Social Council. (2015). The Geneva United Nations Charter on Sustainable Housing. E/ECE/1478/Rev.1. Geneva: Economic Commission for Europe, 1-8.

UNEP. (2013a). Sustainable solutions for social housing: Guidelines for project developers. Paris: UNEP Division of Technology, Industry and Economics.

UNEP. (2013b). The sustainable social housing initiative consultation workshop in India. Proceedings of the Sustainable Social Housing Initiative Consultation Workshop. India Habitat Centre, Delhi, 25 April 2013. New Delhi: United Nations Environment Programme, 1-24.

UN-HABITAT-III-17. (2015). HABITAT-III issue papers: 17 cities and climate change and disaster risk management. New York: United Nations Task Team on HABITAT III. 